\title{
Effect of entacapone, a peripherally acting catechol-O-methyltransferase inhibitor, on the motor response to acute treatment with levodopa in patients with Parkinson's disease
}

\author{
Marcelo Merello, Andrew J Lees, Roy Webster, Michael Bovingdon, Ariel Gordin
}

\begin{abstract}
Catechol-O-methyltransferase (COMT) inhibitors may be useful in the treatment of Parkinson's disease by improving the bioavailability of levodopa and by prolonging its effects. Entacapone (OR-611), a novel COMT inhibitor, which does not cross the blood brain barrier, was assessed in 12 patients with Parkinson's disease and motor fluctuations in a randomised, double-blind, cross-over, single dose study. The magnitude and duration of the therapeutic response to a single dose of $200 \mathrm{mg}$ levodopa/50 mg carbidopa was evaluated after concomitant placebo, or 200 or $800 \mathrm{mg}$ entacapone. A significant increase in the duration of the motor response to levodopa was seen when $200 \mathrm{mg}$ entacapone was given with levodopa/carbidopa. Plasma levodopa concentrations were increased with both doses of the COMT inhibitor. The latency to onset of motor response did not differ significantly between active drug and placebo. Entacapone may prove useful in prolonging the duration of the benefit obtained from individual doses of levodopa.
\end{abstract}

(₹ Neurol Neurosurg Psychiatry 1994;57:186-189)

Catechol-O-methyltransferase (COMT) is an important enzyme involved in the peripheral and central metabolism of dopamine. ${ }^{1}$ In the central nervous system it is believed to exert its major action in the synaptic cleft.

When decarboxylation of levodopa is blocked by peripheral dopa decarboxylase inhibitors (DCIs), O-methylation becomes the most prominent pathway of levodopa catabolism $^{2}$ and leads to the accumulation of 3-O-methyldopa. It has been suggested that 3-O-methyldopa may impair the transport of levodopa across the blood brain barrier and compete with levodopa for decarboxylation within the brain..$^{3-5}$ It has also been proposed that accumulation of 3-O-methyldopa may be a causal factor in the development of motor fluctuations in Parkinson's disease. ${ }^{6}$ This theory, however, has been challenged. The plasma concentrations of 3-O-methyldopa causing a deleterious effect on the clinical response to levodopa in parkinsonian patients are much higher than those found during long term levodopa decarboxylase inhibitor treatment. $^{7-10}$ The oral bioavailability of levodopa is low due to first pass metabolism which is at least partly due to the high activity of COMT in the gut and liver. ${ }^{11} 12$ The combination of a peripheral COMT inhibitor with levodopa/DCI therapy might therefore produce a smoother and more prolonged motor response in patients with Parkinson's disease..$^{1314}$ As early as in 1971 Ericsson $^{15}$ reported beneficial effects with a COMT inhibitor with concomitant reduction in levodopa-induced dyskinesias. More recently, a new generation of COMT inhibitors have been developed, which are much more potent and specific. ${ }^{13} 1416-20$ Fluorodopa positron emission tomography (PET) studies in monkeys and patients with Parkinson's disease have also shown that peripheral COMT inhibitors increase striatal fluorodopa uptake. ${ }^{21-23}$

Entacapone (OR-611) is a highly selective and potent nitrocatechol-structured COMT inhibitor that penetrates the brain poorly, acting mainly in the gut. In animal models of Parkinson's disease, entacapone potentiated and prolonged the therapeutic effect of levodopa in a dose-dependent manner. ${ }^{24} 25$

We have studied the motor response and pharmacokinetics of levodopa in 12 patients with Parkinson's disease and severe motor fluctuations after acute levodopa challenge alone or in combination with two different entacapone doses.

\section{Materials and methods}

Twelve patients from the Department of Neurology, University College and Middlesex Hospitals, London treated with levodopa (11 men and one woman, mean age 58.5 (range 46-71) years), mean duration of disease $14 \cdot 7$ (range 8-24) years), mean daily levodopa dose 1183 (range 300-4250) $\mathrm{mg}$ agreed to participate. The patients were informed about the objectives and design of the study, and informed consent was obtained. The study was approved by the Ethics Committee of the Faculty of Clinical Sciences, University College School of Medicine, London.

All patients fulfilled the United Kingdom Parkinson's Disease Brain Bank clinical diagnostic criteria for idiopathic Parkinson's disease $^{26}$ and had a clear response to an acute challenge with levodopa. Patients with secondary parkinsonism, severe dementia, unstable cardiac, renal, pulmonary, or gastrointestinal 
disease, and women of childbearing age were excluded. Those patients receiving drugs for treating parkinsonism other than levodopa continued on these unchanged throughout the study.

The magnitude and duration of the therapeutic response of a single dose of $200 \mathrm{mg}$ levodopa in combination with $50 \mathrm{mg}$ carbidopa (two tablets of Sinemet plus, Merck, Sharp, and Dohme were evaluated after concomitant administration of placebo, or 200 or $800 \mathrm{mg}$ entacapone (Orion Pharmaceutica, Espoo, Finland). The pharmacokinetics and metabolism of levodopa were also studied. The study followed a double-blind, crossover design and the order of medication was randomised.

The single doses of levodopa/carbidopa and study drugs (entacapone/placebo). were given simultaneously at 8.00 am in the fasting state after an overnight drug holiday.

Clinical scoring was carried out at 15-30 minute intervals from 7.30 am to noon. If the drug effect persisted after the noon rating, assessments were continued at 30 -minute intervals until motor scores had returned to baseline. The motor function was assessed by (1) a tapping test - the number of times the patient could alternately tap two laboratory counters $20 \mathrm{~cm}$ apart in $30 \mathrm{~s}$ with the more severely affected hand; (2) a walking test - the time required to rise from an armless chair, walk $6 \mathrm{~m}$, turn, and sit down (cut off time $30 \mathrm{~s}$ ); (3) a 5-point dyskinesia scale; and (4) an overall global score $(-4=$ severe, disabling symptoms to $0=$ normal to $+4=$ severe disabling dyskinesia). The criteria used to assess the duration of response and the time to "switch off" have been previously described. ${ }^{27}$

Plasma concentrations of levodopa, 3-Omethyldopa, and the dopamine metabolites dihydroxyphenyl acetic acid and homovanillic acid were measured by high performance liquid chromatography (HPLC). ${ }^{28}$

\section{STATISTICS}

For each clinical variable, the mean duration of the difference of the means and the mean of the maximum values for each patient in each treatment sequence were compared by the Wilcoxon rank test. Statistical analysis of the plasma concentrations was carried out with analysis of variance and the NewmanKeuls test.

\section{Results}

\section{CLINICAL RESPONSE}

The latency to peak motor response was not significantly different between the three trial days, but the duration of effect when entacapone was administered with levodopa was increased by a mean of 34.5 minutes (200 $\mathrm{mg}$ ) and 39 minutes $(800 \mathrm{mg})$, respectively, compared with the placebo day (table). The difference in the duration between the placebo and $200 \mathrm{mg}$ days was statistically significant $(\mathrm{p}<0.05)$ by paired $t$ test, but significance was not quite reached between the placebo and $800 \mathrm{mg}$ day due to a larger variation in response (table). When $200 \mathrm{mg}$ of entacapone was used, the overall scores for tapping $(p<0.05)$, dyskinesias $(p<0.005)$, and global score $(p<0.05)$ were significantly higher and the walking time significantly lower $(p<0.05)$ than on the placebo day (figs $1 \mathrm{a}$ and b). The global score with $200 \mathrm{mg}$ of entacapone was also higher $(p<0.05)$ than with $800 \mathrm{mg}$, but no statistically significant differences were found between the placebo day and the $800 \mathrm{mg}$ day when maximum values were compared (fig lb). The $800 \mathrm{mg}$ dose of entacapone gave a higher peak score for dyskinesias than placebo $(p<0.05)$. The maximum tapping score with $200 \mathrm{mg}$ entacapone was significantly higher than with $800 \mathrm{mg}$ ( $\mathrm{p}<0.05$; fig 1a).

Two patients showed a biphasic motor response when they received $800 \mathrm{mg}$ entacapone (table). Pronounced waning of the motor response was followed in these patients by a second spontaneous motor improvement lasting 45 to 60 minutes. These findings are not included in the statistics. Patient 6 did not "switch on" at all either with placebo or with $800 \mathrm{mg}$ of entacapone. Patient 7 also failed to "switch on" with $800 \mathrm{mg}$ of entacapone. These patients are not included in the calculation of the latency and duration of the motor response to levodopa. By contrast, all the patients on $200 \mathrm{mg}$ entacapone

Table Motor response (time in minutes)

\begin{tabular}{|c|c|c|c|c|c|c|}
\hline \multirow{2}{*}{\multicolumn{3}{|c|}{ Placebo }} & \multicolumn{4}{|l|}{ Entacapone } \\
\hline & & & \multicolumn{2}{|l|}{$200 \mathrm{mg}$} & \multicolumn{2}{|l|}{$800 \mathrm{mg}$} \\
\hline Patient & Latency & Duration & Latency & Duration & Latency & Duration \\
\hline $\begin{array}{l}1 \\
2 \\
3 \\
4 \\
5 \\
6 \dagger \\
7 \dagger \\
8 \\
9 \\
10 \\
11 \\
12 \\
\text { Mean (SD) }\end{array}$ & $\begin{array}{l}105 \\
105 \\
60 \\
45 \\
45 \\
\text { NR } \\
45 \\
30 \\
75 \\
30 \\
105 \\
60 \\
66(30 \cdot 17)\end{array}$ & $\begin{array}{l}120 \\
105 \\
165 \\
165 \\
165 \\
\text { NR } \\
90 \\
150 \\
105 \\
180 \\
30 \\
105 \\
129(45 \cdot 39)\end{array}$ & $\begin{array}{l}45 \\
75 \\
60 \\
45 \\
45 \\
60 \\
120 \\
45 \\
30 \\
45 \\
90 \\
60 \\
54(17.61)\end{array}$ & $\begin{array}{l}195 \\
120 \\
240 \\
180 \\
225 \\
60 \\
45 \\
180 \\
60 \\
225 \\
60 \\
150 \\
163.5(65 \cdot 36)^{\star}\end{array}$ & $\begin{array}{l}30 \\
60 \\
45 \\
60 \\
90 \\
\text { NR } \\
\text { NR } \\
75 \\
120 \\
30 \\
105 \\
90 \\
70.5(30.86)\end{array}$ & $\begin{array}{l}360 \\
150 \\
105 \\
270 \\
90 \\
\text { NR } \\
\text { NR } \\
210 \\
105 \\
210 \\
60 \\
120 \\
168(93 \cdot 75)\end{array}$ \\
\hline
\end{tabular}

${ }^{\star} \mathrm{p}<0.01 v$ placebo.

These patients are not included in the statistical analysis.

NR = No response. 
Figure 1 Curves of the means of different clinical variables in 12 patients after acute administration of levodopa plus placebo or 200 or 800 mg entacapone. (A) Number of taps in $30 s$ with the more disabled hand; (B) global score. ( $\square)$ placebo; ( $\triangle$ ) entacapone $200 \mathrm{mg}$; (O) entacapone $800 \mathrm{mg}$.
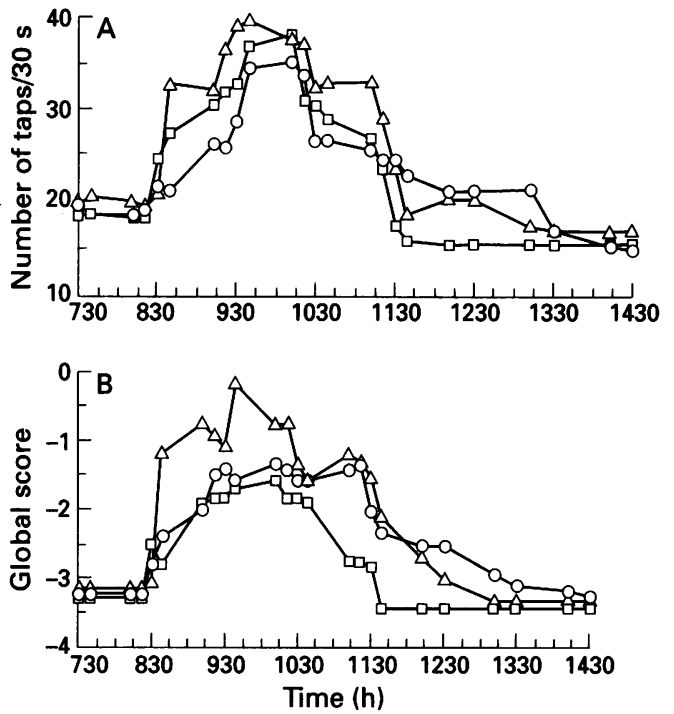

Figure 2 Means of the plasma concentrations for (A) levodopa and (B) homovanillic acid ( $H V A)$. (O) placebo; $(\square$ entacapone $200 \mathrm{mg}$ ( $\square$ ) entacapone $800 \mathrm{mg}$
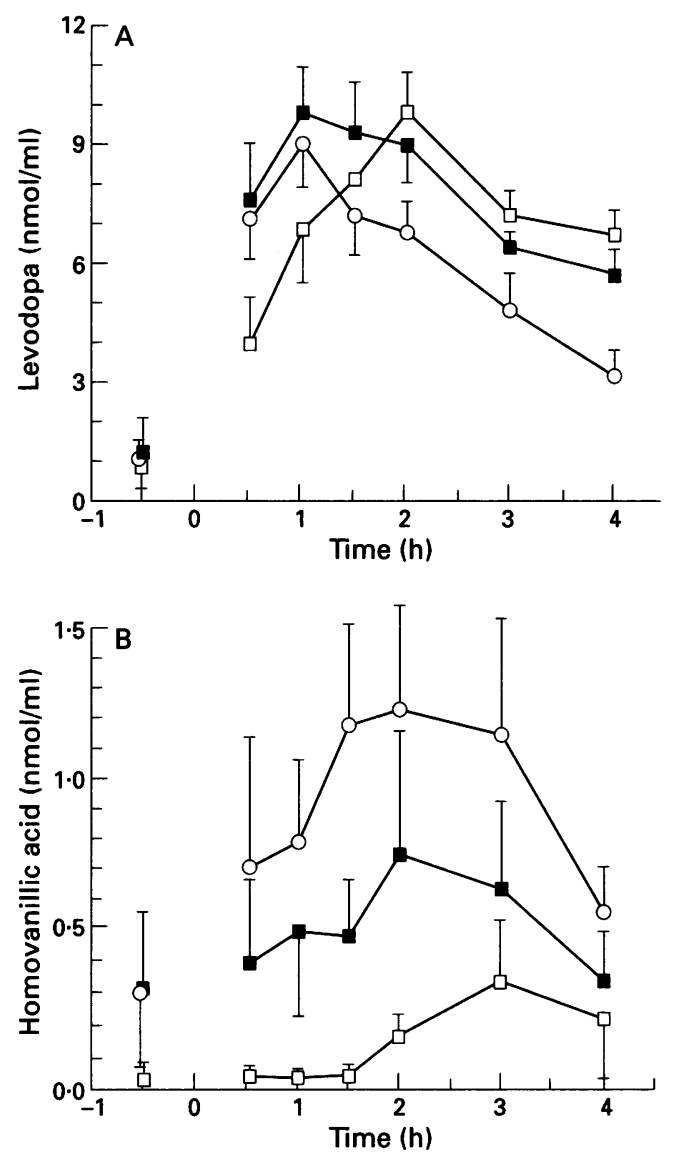

showed clinical benefit and 10 out of 12 patients given $200 \mathrm{mg}$ entacapone had a duration of motor response longer than that found with placebo.

SAFETY

Routine clinical haematological and biochemical variables did not change significantly during the study. No adverse events were reported but a transient strong orange colouration to the urine was seen in many patients, probably due to entacapone.
PHARMACOKINETIC ANALYSIS

Entacapone significantly delayed the fall in plasma levodopa concentrations $(p<0.05)$. The higher dose also delayed the attainment of peak plasma levodopa concentrations but neither 200 nor $800 \mathrm{mg}$ entacapone increased the magnitude of the levodopa peak (fig 2a). The plasma dihydroxyphenyl acetic acid concentrations were significantly increased and the homovanillic acid concentrations reduced ( $p<0.01$ ) with $800 \mathrm{mg}$ of entacapone, but not with $200 \mathrm{mg}$ (fig 2b). Plasma 3-Omethyldopa concentrations were not significantly different during the three days of the trial.

\section{Discussion}

Levodopa pharmacokinetics play an important part in determining the duration of the motor response in Parkinson's disease. ${ }^{292829}$ Peripherally acting COMT inhibitors, by preventing conversion of levodopa to 3-Omethyldopa, might therefore provide a means of extending the duration of motor benefit from individual levodopa doses. The two novel peripherally acting COMT inhibitors do not significantly alter striatal COMT activity in animal studies. ${ }^{1625}$ They also seem to be much less toxic than the first generation COMT inhibitors (Gallates, Tropolone, U0521). ${ }^{13-1530}$ The first studies in normal healthy subjects indicate that nitecapone and entacapone should be safe. ${ }^{19}{ }^{2031-34}$ At the present time it is unclear whether a COMT inhibitor with both peripheral and central effects would confer any greater therapeutic benefit, or whether it could be safely used in combination with monoamine oxidase inhibitors. ${ }^{35}$

The mean increase of about $30 \%$ in the duration of motor response (129 minutes to 163 and 169 minutes) after entacapone intake is appreciable when compared with that reported for selegiline ${ }^{36}$ or sustained release levodopa formulations in acute dose studies. ${ }^{37}$ If these findings could be reproduced with chronic repeated dosing of entacapone, a further 30 minute motor improvement from each levodopa dose could result in up to two to four hours more waking mobility each day in parkinsonian patients. This may also permit a reduction in the requirement in the total daily dose of levodopa.

Patients receiving entacapone had somewhat more dyskinesias indicating increased bioavailability of levodopa to the brain and providing clinical support for the PET studies, which have shown increased striatal fluorodopa uptake. ${ }^{21-23}$

In previous studies we have found that patients "switched off" when plasma levodopa concentrations fell to around half the peak values in an individual patient. ${ }^{28}$ If this is applied to the present study, however, a somewhat greater prolongation of motor response with entacapone would have been predicted than that found. The recorded motor response and the plasma levodopa 
concentrations correlated closely. No difference in peak plasma concentrations of levodopa were found between placebo and entacapone, but the slopes of the curves were more gradual and at four hours after giving levodopa plasma concentrations were significantly higher with 200 and $800 \mathrm{mg}$ of entacapone. This is in accordance with results in animals and healthy volunteers..$^{20} 253438$ The delay in the attainment of peak plasma levodopa concentrations with $800 \mathrm{mg}$ entacapone might be explained by interference with levodopa absorption in the gut.

The two patients who failed to "switch on" with placebo or $800 \mathrm{mg}$ entacapone normally took $500 \mathrm{mg}$ levodopa in the morning instead of the standard $200 \mathrm{mg}$ dose used in this study. The fact that $200 \mathrm{mg}$ entacapone with $200 \mathrm{mg}$ levodopa "switched them on" might indicate possible levodopa sparing effects. Both patients had very high 3-O-methyldopa concentrations.

The lower concentrations of the O-methylated and deaminated catabolite of dopamine, homovanillic acid, on both entacapone days and the increased production of the deaminated metabolite, dihydroxyphenyl acetic acid, provide confirmatory evidence that entacapone systematically reduces COMT activity. The finding that these effects were greater with 800 than with $200 \mathrm{mg}$ entacapone implies that COMT inhibition was dose related, even if the improvement in motor response to levodopa was not.

The plasma concentrations of 3-O-methyldopa in patients on chronic levodopa DCI therapy are very high and the half life of 3-Omethyldopa is long (15-16 hours) compared with levodopa (one hour). ${ }^{2}$ Therefore plasma concentrations of 3-O-methyldopa should not be reduced by a single dose of entacapone. To reduce the plasma concentrations of 3-Omethyldopa chronic COMT inhibition would be required.

We thank Orion Pharmaceutica, Espoo, Finland for the generous supply of entacapone.

1 Carlsson A. Functional significance of drug induced changes in brain monoamine levels. In: Himwich $\mathrm{HE}$ Himwich WA, eds. Biogenic amines. Progress in Brain Research. Amsterdam: Elsevier, 1964;8:9-27.

2 Nutt JG, Fellman JH. Pharmacokinetics of L-dopa. Clin Neuropharmacol 1984;7:35-49.

3 Muenter MD, Dinapoli RP, Sharpless NS, Tyce GM. 3-O-methyldopa, L-dopa and trihexyphenidyl in the treatment of Parkinson's disease. Mayo Clin Proc 1973, 48:173-83.

4 Wade LA, Katzman R. 3-O-methyldopa uptake and inhibition of L-dopa at the blood-brain barrier. Life $S_{c i}$ inhibition of L-d

5 Gervas J, Muradas B, Bazan E, Aguado E, de Yebenes J. Effects of 3-OM-dopa on monoamine metabolism in rat brain. Neurology 1983;33:278-82.

6 Calne DB, Reid JL, Vakil SD. Parkinsonism treated with 3-O-methyldopa. Clin Pharmacol Ther 1972;14:386-9.

7 Cedarbaum JM, Kutt H, McDowell FH. Clinical significance of the relationship between O-methyldopa levels and levodopa intake. Neurology 1988;38:533-6.

8 Fabbrini G, Juncos $\pi$, Mouradian MM, Serrati S, Chase TN. 3-O-methyldopa and motor fluctuations in Parkinson's disease. Neurology 1987;37:856-9.

9 Gancher ST, Nutt JG, Woodward WR. Peripheral pharmacokinetics of levodopa in untreated, stable and fluctuating Parkinsonian patients. Neurology 1987;37: 940-4.

10 Nutt JG, Woodward WR, Gancher ST, Merrick D. 3-O- methyldopa and response to levodopa in Parkinson's disease. Ann Neurol 1987;21:584-8.

11 Nissinen E, Tuominen T, Perhoniemi V, Kaakkola S Catechol-O-methyltransferase in human and rat small intestine. Life Sci 1988;42:2609-14.

12 Ball $P$, Knuppen R, Haupt $M$, Breuer $H$. Purification and properties of catechol-O-methyltransferase of human liver. Eur $\mathcal{F}$ Biochem 1971;21,517-25.

13 Männistö PT, Kaakkola S. Rationale for selective COMT inhibitors as adjuncts in the drug treatment of Parkinson's disease. Pharmacol Toxicol 1990;66:317-23.

14 Männistö PT, Kaakkola S. New selective COMT inhibitors: useful adjuncts for Parkinson's disease? Trends Pharmacol Sci 1989;10:54-6.

15 Ericsson $\mathrm{AD}$. Potentiation of the L-dopa effect in man by the use of catechol-O-methyltransferase inhibitors. f Neurol Sci 1971;14:193-7.

16 Nissinen E, Lindén I, Schultz E, Kaakkola S, Männistö PT, Pohto P. Inhibition of catechol-O-methyltransferase activity by two novel disubstituted catechols in the rat. Eur $f$ Pharmacol 1988;153:263-9.

17 Borgulya J, Bruderer H, Bernauer $K$, Zürcher G, Da Prada M. Catechol-O-methyltransferase-inhibiting pyrocatechol derivates-synthesis and structure activity studies. Helv Clin Acta 1989;72:952-68.

18 Bäckström R, Honkanen E, Pippuri A, et al. Synthesis of some novel potent and selective catechol-O-methyltransferase (COMT) inhibitors. F Med Chem 1989;32: 841-6.

19 Kaakkola S, Gordin A, Järvinen N, Wikberg T, Schultz E, Nissinen $E$, et al. Effect of a novel catechol-O-methyltransferase inhibitor, Nitecapone, on the metabolism of L-dopa in healthy volunteers. Clin Neuropharmacol 1990;13:436-47.

20 Keränen $\mathrm{T}$, Gordin A, Karlsson $\mathrm{M}$, et al. Effect of the novel catechol-O-methyltransferase inhibitor OR-611 in healthy volunteers. Neurology 1991;41(suppl 1):345P

21 Leger G, Reches A, Cedarbaum J, et al. PET studies in Cynomolgus monkeys show that OR-611 increases striatal fluorodopa uptake. Neurology 1991;41 (suppl 1): 915S.

22 Leger G, Reches A, Cedarbaum J, et al. Inhibition of 3-OMethylfluorodopa formation with OR-462: Attempts to simplify the Fluorodopa model for PET analysis. Neurology 1990;40(suppl 1):152S.

23 Laihinen A, Rinne JO, Rinne UK, et al. [18 F]-6Fluorodopa PET scanning in Parkinson's disease after selective COMT inhibition with nitecapone (OR-462). Neurology 1992;42:199-203.

24 Etemadzadeh E, Koskinen L, Kaakkola S. Computerized rotometer apparatus for recording circling behaviour. Methods Find Exp Clin Pharmacol 1989;11:399-407.

25 Nissinen E, Lindén I-B, Schultz E, Pohto P. Biochemical and pharmacological properties of a peripherally acting catechol-O-methyltransferase inhibitor Entacapone. Naunyn Schmiedebergs Arch Pharmacol 1992;346:262-6.

$26 \mathrm{Gibb}$ WR, Lees AJ. The relevance of the Lewy body to the pathogenesis of idiopathic Parkinson's disease. $\mathcal{F}$ Neurol Neurosurg Psychiatry 1988:51:745-52.

27 Hughes AJ, Lees AJ, Stern GM. Apomorphine test to predict dopaminergic responsiveness in parkinsonian syndromes. Lancet 1990;336:32-4.

28 Kempster PA, Frankel JP, Bovingdon M, Webster R, Lees AJ, Stern GM. Levodopa peripheral pharmacokinetics and duration of motor response in Parkinson's disease. and duration of motor response in Parkinson's

29 Gancher ST, Nutt JG, Woodward WR. Response to brief levodopa infusions in Parkinsonian patients with and levodopa infusions in Parkinsonian patients with and
without motor fluctuations. Neurology 1988;38:712-6.

30 Reches A, Fahn S. Catechol-O-methyltransferase and Parkinson's disease. Adv Neurol 1984;40:171-9.

31 Sundberg S, Scheinin M, Ojala-Karlsson P, Kaakkola S, Akkila J, Gordin A. Exercise hemodynamics and catecholamine metabolism after COMT inhibition with nitecapone. Clin Pharmacol Ther 1990;48:356-64.

32 Teräväinen $H$, Kaakkola $S$, Järvinen $M$, Gordin A. Selective COMT inhibitor, nitecapone, in Parkinson's disease. Neurology 1990;40(suppl 1):271

33 Teräväinen $\mathbf{H}$, Kaakkola S, Gordin A. Clinical effect of COMT inhibition in L-dopa-treated patients with Parkinson's disease. Neurology 1992;42(suppl 3):442.

34 Keränen T, Gordin A, Harjola V-P, et al. The effect of catechol-O-methyltransferase inhibition by entacapone on the pharmacokinetics and metabolism of levodopa in healthy volunteers. Clin Neuropharmacol 16:145-50.

35 Männistö PT, Ulmanen I, Lundström K, et al. Characteristics of catechol-O-methyltransferase (COMT) and properties of selective COMT inhibitors. Prog Drug Res 1992; 39:291-350.

36 Lees AJ, Shaw KM, Kohout $\mathrm{L}$, et al. Deprenyl in Parkinson's disease. Lancet 1977;2:791-3.

37 Poewe WH, Lees AJ, Stern GM. Treatment of motor fluctuations in Parkinson's disease with an oral sustained release preparation of L-dopa. Clinical and pharmacokinetic observations. Clin Neuropharmacol 1986;9:430-9.

38 Cedarbaum JM, Leger G, Guttman M. Reduction of circulating 3-O-methyldopa by inhibition of catechol-Omethyltransferase with OR-611 and OR-462 in cynomolous monkeys: Implications for the treatment of Parkinson's disease. Clin Neuropharmacol 1991;14: 330-42. 